\title{
Fragmentación y conectividad de la cobertura natural a nivel cantonal en Costa Rica durante los años 2000 y 2015
}

\section{Fragmentation and connectivity of the natural cover at county level in Costa Rica, during 2000 and 2015 years}

\author{
Carlos Morera-Beita ${ }^{1}$ \\ Luis Fernando Sandoval-Murillo ${ }^{2}$ \\ Universidad Nacional, Costa Rica
}

\begin{abstract}
Resumen
En esta investigación se plantea la formulación de un índice de fragmentación/conectividad que valora la condición de las coberturas naturales a nivel de cantones para Costa Rica, basado en la distribución espacial, considerando las variables: superficie del cantón, la superficie de cobertura natural, el número de fragmentos y distancia de vecindad entre los fragmentos de la cobertura natural, para los años 2000 y 2015. Se utilizaron las imágenes Landsat 7 para el año 2000 y Landsat 8 para el año 2015, donde se derivaron las categorías de uso de la tierra para cada año mediante clasificación supervisada con el software ERDAS y con el ArcMap10.5, se estimaron los índices biométricos usando la ecuación de Vargas (2008), la cual para su aplicación fue modificada. Dentro de los resultados se identificó los cantones que presentan mayor o menor fragmentación y conectividad de su cobertura natural durante el periodo de estudio.
\end{abstract}

Palabras clave: cobertura natural, uso de la tierra, fragmentación, conectividad, índice biométrico

1 Académico, Escuela de Ciencias Geográficas. Universidad Nacional, Costa Rica. Correo electrónico: cmorera@una.cr

2 Académico, Escuela de Ciencias Geográficas. Universidad Nacional, Costa Rica. Correo electrónico: luis. sandoval.murillo@una.cr

Este artículo corresponde a la ponencia presentada en el I Congreso Centroamericano de Ciencias de la Tierra y el Mar, realizado en San José, Costa Rica, del 13 al 16 de noviembre de 2017. 


\begin{abstract}
This research proposes the formulation of a fragmentation / connectivity index that assesses the condition of natural cover at the canton level for Costa Rica based on spatial distribution considering the variables: area of the county, the natural coverage area, the number of fragments and distance of neighborhood between the fragments of the natural cover, for the years 2000 and 2015. The images Landsat 7 for the year 2000 and Landsat 8 for the year 2015 were used where the land use categories for each year were derived through supervised classification with ERDAS software and with ArcMap10.5 biometric indices were estimated using the Vargas equation (2008) which was modified for its application. Within the results, we identified the cantons that present greater or lesser fragmentation and connectivity of their natural coverage during the study period.
\end{abstract}

Keyword: nature cover, land use, fragmentation, connectivity, biometric index.

\title{
Introducción
}

La conformación del paisaje refleja la impronta de las actividades humanas, las cuales determinan su heterogeneidad (Morera y Sandoval, 2018). Para evaluar los patrones espaciales que conforman los elementos del paisaje se han propuesto los índices biométricos que formulan ecuaciones matemáticas para valorar la disposición de las variables del paisaje (Liu, Li y Chen, 2010). En los últimos años el desarrollo de las tecnologías de Sistemas de Información Geográfica y teledetección (SIGT) han incidido en la proliferación de estudios que valoran las los patrones espaciales del paisaje y algunas se han centrado en la formulación y la aplicabilidad de estos índices. En el caso de Costa Rica, autores como: Veldkamp y Fresco (1996); Calvo, Watson, Bolaños, Quesada, Sánchez, Gonzáles y Ramírez (1999); Sánchez, Foley, Hamilton, Calvo, Arroyo y Jiménez, (2002), Calvo y Ortiz (2011) Morera (2010); y Morera y Sandoval (2000, 2013, 2015) han abordado esta temática.

Los resultados de las anteriores investigaciones evidencian la recuperación de la cobertura boscosa en el país, sin embargo, no existen estudios que evalúen el comportamiento de la cobertura natural a nivel de cantones, para lo cual los índices biométricos son un método adecuado para este fin. Por lo que es necesario evaluar la distribución espacial de los ecosistemas naturales donde se considera no solo la superficie, sino aspectos relacionados a la disposición y grado de conectividad ecológica que se transforman en criterios considerados para la toma de decisiones, en cuanto a políticas de ordenamiento territorial orientadas a la conservación y conectividad ecológica. 
Considerando la anterior necesidad, esta investigación plantea la formulación de un índice de fragmentación/conectividad que valora la condición de los ecosistemas naturales en cada cantón del país, basado en la relación entre: el área del cantón, con la superficie de cobertura natural, el número de fragmentos y distancia de vecindad entre los fragmentos de la cobertura natural, para los años 2000 y 2015 utilizando imágenes Landsat. Este permite la identificación de cuáles son los cantones que presentan mayor o menor fragmentación/conectividad de su cobertura natural durante este periodo de estudio.

\section{Metodología}

Como información básica de esta investigación, se elaboraron los levantamientos de las coberturas de uso de la tierra para los años 2000 y 2015, utilizando imágenes satelitales LandSat7 y LandSat8 con una resolución espacial de 30 metros. Las imágenes satelitales de acuerdo con Ambrosio, Gonzales y Arévalo (s.f.), idealmente, capturadas en dos diferentes imágenes de satélite (con el mismo sensor) deberían aparecer con los mismos valores de intensidad. En la práctica, lo anterior no sucede debido a las inevitables condiciones atmosféricas y de iluminación desiguales, por lo que se hace necesaria la corrección radiométrica de las imágenes, en la cual, según Martínez, Palá y Arbiol (2004) es necesaria para modelar adecuadamente parámetros físicos realistas y consistentes, al abordar estudios multi-temporales, mismos que facilitan el proceso de clasificación supervisada y de fotointerpretación.

El procesamiento de la imagen consistió en dos etapas. Primeramente, en la identificación de las coberturas a utilizar, de acuerdo con la resolución espacial como: áreas urbanas, cuerpos de agua, cultivos, vegetación anegada y manglares, las cuales fueron delimitadas por fotointerpretación. Para reducir la confusión con otras categorías por medio de una máscara, las coberturas se extrajeron de las imágenes principales, permitiendo clasificar únicamente aquellos sectores de la imagen que no habían sido procesadas.

En una segunda etapa se tomó las muestras en la imagen de cada firma espectral de las coberturas faltantes por clasificar como; bosques de alta densidad y bosque de baja densidad, pastos para las cuales se tomaron 70 muestras por cada una de ellas en las seis imágenes que conforman el territorio nacional, resultado 1260 puntos para ambos periodos. Con la 
reclasificación supervisada se evidenció que no representan más de un 10 $\%$ de confusión entre ellas, procedimiento que se realizó con el software ERDAS. Posteriormente, cada categoría de uso se convirtió de ráster a vector y se integró en una capa vectorial para establecer el mosaico de uso por cobertura para el país. Posteriormente, se procedió a la limpieza del mosaico de acuerdo con su unidad mínima cartografiable, y según lo establecido por Priego, Bocco, Mendoza y Garrido (2008), permite lograr coherencia en la representación espacial, así como eficiencia en la lectura y utilidad del mapa en formato impreso. Para el área de estudio se utilizó como unidad mínima a representar cartográficamente un área de $3600 \mathrm{~m}^{2}$ dada por la siguiente fórmula:

\section{$\mathrm{UMC}=(\operatorname{Lpv} \times \mathbf{E} \times 3)^{2}$}

Donde:

UMC: Unidad Mínima Cartografiable, expresada en $\mathrm{m}^{2}$.

Lpv: Límite de percepción visual ( $0.2 \mathrm{~mm}$ a escala del plano) expresado en $m$.

E: Escala del mapa.

La UMC permitió realizar uniones de las coberturas que no cumplen con dicha área, las cuales son agregadas a las más cercana y para este caso la mayoría estaban inmersas dentro de polígonos más extensos, lo cual facilito su agrupación. Este procedimiento se realizó en el software ArcGis con las extensiones (Layer and table views - Make Feature Layer) - (Generalization - Eliminate). Las categorías identificadas se detallan en la tabla 1.

Tabla 1. Categorías Coberturas de Uso de la Tierra, año 2000- 2015

\begin{tabular}{|c|c|}
\hline Categoría & Caracterización \\
\hline $\begin{array}{l}\text { Bosque de alta densidad } \\
\text { (BAD) }\end{array}$ & $\begin{array}{l}\text { Ecosistemas boscosos caracterizados por la dominancia de las } \\
\text { estrategas } \mathrm{K} \text {, un dosel abundante que limita la luminosidad } \\
\text { en el estrato herbáceo y arbustivo, que presenta una limitada } \\
\text { presencia de actividad antrópica, que se identifican en las } \\
\text { imágenes como áreas con densa densidad del dosel. }\end{array}$ \\
\hline $\begin{array}{l}\text { Bosque de baja } \\
\text { densidad (BBD) }\end{array}$ & $\begin{array}{l}\text { Bosques que presentan una contundente intervención humana, } \\
\text { generados por procesos de regeneración natural después } \\
\text { de eliminarse total o de forma selectiva el bosque primario, } \\
\text { debido a actividades antrópicas o por eventos naturales }\end{array}$ \\
\hline
\end{tabular}




\begin{tabular}{|l|l|}
\hline \multicolumn{1}{|c|}{ Categoría } & \multicolumn{1}{c|}{ Caracterización } \\
\hline Páramo & $\begin{array}{l}\text { Ecosistemas montano intertropical localizados a más de 3200 } \\
\text { msnm, dominado por vegetación húmeda de tipo matorral } \\
\text { (arbustos) de origen andinos con alta presencia de endemismos } \\
\text { debido al aislamiento. }\end{array}$ \\
\hline Vegetación anegada & $\begin{array}{l}\text { Sesquespantanosos que ocupan espacios conalta sedimentación } \\
\text { donde se mezcla el ambiente marino y el terrestre. }\end{array}$ \\
\hline Pasto arbolado & $\begin{array}{l}\text { Eliminación parcial (menos del 50\%) de los árboles y } \\
\text { remplazado por vegetación de gramíneas debido razones } \\
\text { antrópicas, especialmente ganadería extensiva. }\end{array}$ \\
\hline Cultivos & $\begin{array}{l}\text { Son áreas con ocupación agrícola que puede ser permanentes } \\
\text { o estaciónales. }\end{array}$ \\
\hline Urbano y Residencias & $\begin{array}{l}\text { Están representados por la ocupación urbano- residencial, } \\
\text { acompañado de servicios públicos institucionales, industrial, } \\
\text { comercial. }\end{array}$ \\
\hline
\end{tabular}

Fuente: Adaptado de Morera y Sandoval, 2015.

Las categorías de uso de la tierra en la tabla 1, se reclasificaron en dos grupos, una en condiciones naturales donde se consideraron coberturas de bosque, paramo, manglar y vegetación anegada; y otra no natural asociada a las actividades antrópicas como pastos arbolados, cultivos, y urbano como se muestra en la tabla 2 , las cuales no fueron consideradas en el presente estudio.

Tabla 2. Coberturas clasificadas según categoría natural y no natural

\begin{tabular}{|l|l|}
\hline \multicolumn{1}{|c|}{ Categoría } & \multicolumn{1}{c|}{ Coberturas } \\
Natural & Bosque de alta densidad (BAD) \\
& Bosque de baja densidad (BBD) \\
& Páramo \\
& Manglar \\
& Vegetación anegada \\
\hline No Natural & Pasto arbolados \\
& Cultivos \\
& Urbano y Residencias \\
\hline
\end{tabular}

Fuente: Elaboración propia 
Con la agrupación en natural y no natural, se excluyeron las áreas protegidas bajo propiedad del estado como son las categorías de parques nacionales y reserva Biológica (mapa 1), lo cual se justifica por que los procesos de alteración y fragmentación son mínimos, así mismo generarían un sesgo, aparte que el objetivo de este índice es analizar los patrones de fragmentación/conectividad de la cobertura boscosa, el cual se centra en espacios con una fuerte actividad antrópica, que se aglutina fuera de estas áreas. Definida la estructura del paisaje, se procedió a realizar por cada cantón la estimación de los índices de paisaje considerando elementos como: tipo de cobertura, número de fragmentos, tamaño medio y distancia de vecindad de las coberturas naturales, aplicando la extensión PATCH ANALYST del software ArcGis para el cálculo de variables. Por otra parte, la escala de las imágenes utilizadas permitió la identificación de las coberturas comprendidas en la tabla 1, mismas que fue identificadas por Morera y Sandoval, (2016). Además, se modificó la ecuación de fragmentación/conectividad aplicada por Vargas (2008) a nivel de cada cantón donde la original era:

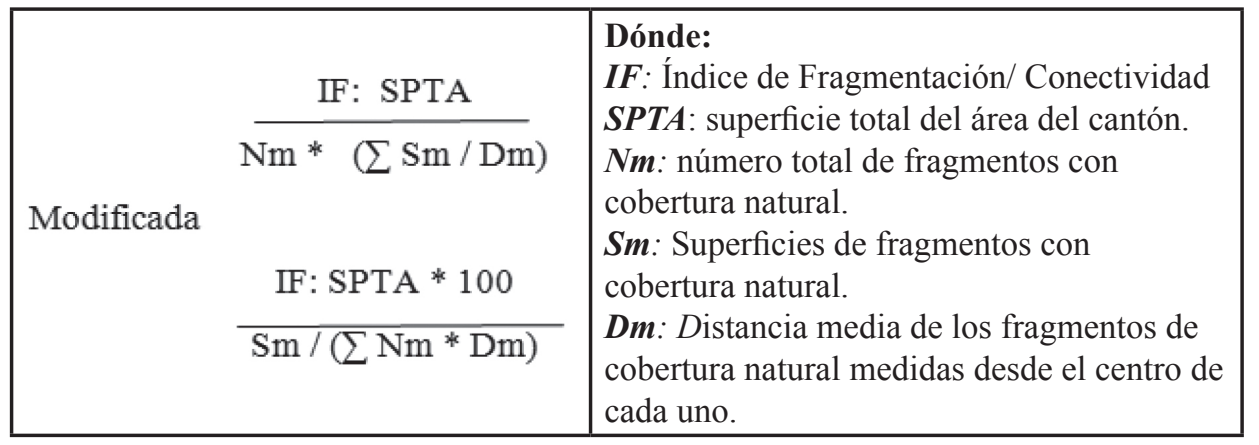

Los datos obtenidos a partir de la aplicación de la fórmula para cada cantón, se clasificaron en 3 clases (tabla 3) basada en la experiencia de otras investigaciones realizadas como Morera y Sandoval, (2013); Morera, y Sandoval, (2015) y Morera y Sandoval, (2016). La nivel bajo que tiene un rango de 0.00 a 3:00 y que se caracteriza por procesos mínimos de fragmentación, el nivel moderado que presenta valores entre 3.01 y 15:00 con un procesos medios de fragmentación y conectividad; y el alto que se caracteriza con valores de más 15:01 dominado por procesos intensos de fragmentación de los ecosistemas naturales. 
Carlos Morera-Beita - Luis Fernando Sandoval-Murillo

Fragmentación y conectividad de la cobertura natural a nivel cantonal en Costa Rica durante los años 2000 y 2015

Tabla 3. Rangos y valores del Índice de Fragmentación/Conectividad

\begin{tabular}{|l|l|l|}
\hline $\begin{array}{c}\text { Rango de Índice de } \\
\text { Fragmentación/Conectividad }\end{array}$ & \multicolumn{1}{|c|}{$\begin{array}{c}\text { Valores del Índice de } \\
\text { Fragmentación/Conectividad }\end{array}$} & Característica ecológica \\
\hline Bajo & $0.00-3.00$ & $\begin{array}{l}\text { Mínimos procesos de } \\
\text { fragmentación. }\end{array}$ \\
\hline Moderado & $3.01-15.00$ & $\begin{array}{l}\text { Procesos de } \\
\text { fragmentación } \\
\text { moderados }\end{array}$ \\
\hline Alto & Más de 15.01 & $\begin{array}{l}\text { Altos procesos de } \\
\text { fragmentación }\end{array}$ \\
\hline
\end{tabular}

Fuente: Elaboración propia.

Mapa 1. Áreas protegidas excluidas (Parque Nacionales y Reservas Biológicas)

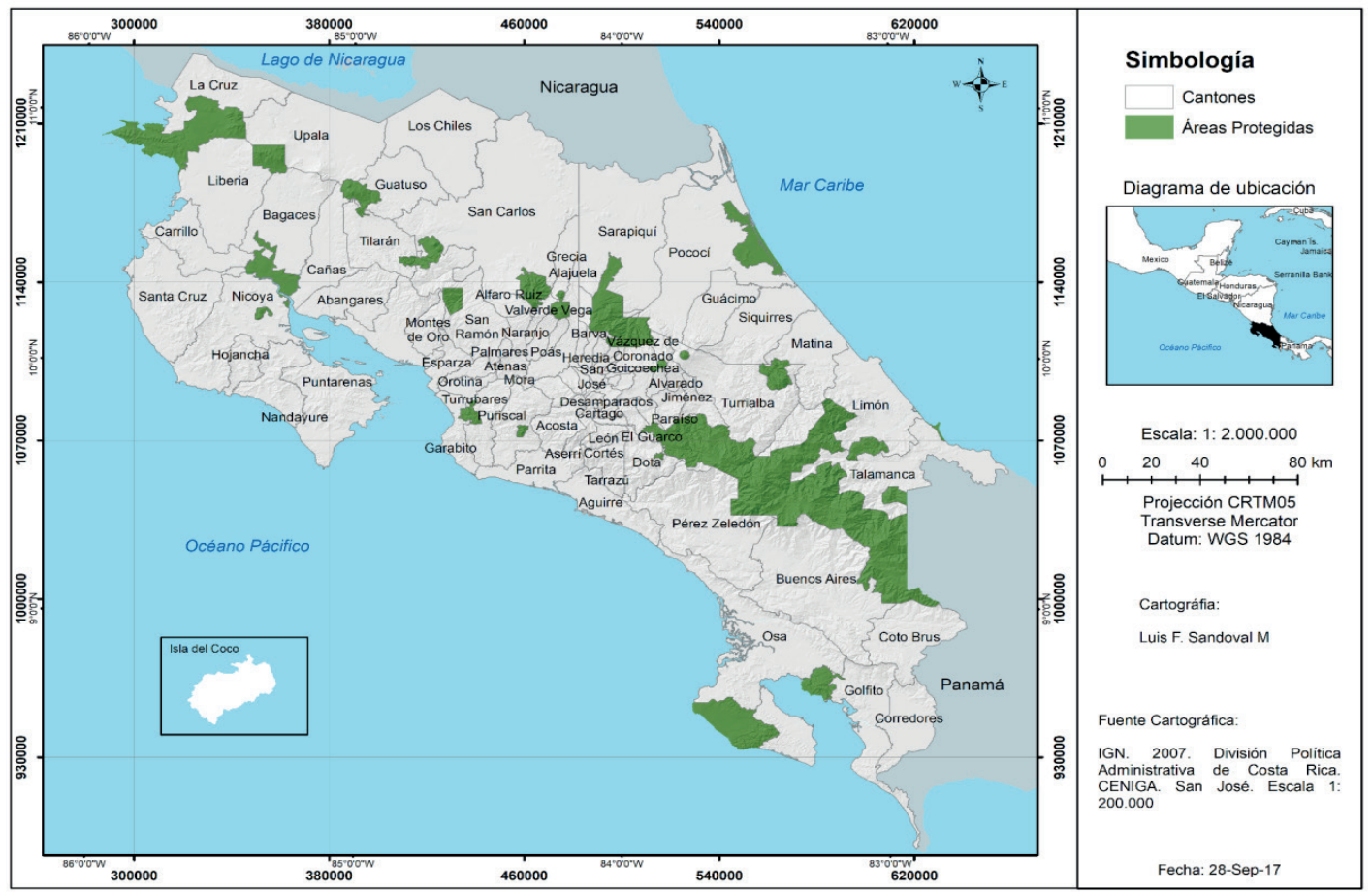




\section{Análisis de Resultados}

\section{Coberturas de uso de la tierra a nivel nacional}

El grafico 1, muestra la distribución de la cobertura de uso de la tierra para Costa Rica en el periodo 2000 - 2015. Donde se evidencia una recuperación de la cobertura boscosa, clasificada en alta densidad siendo $13 \%$ en el 2000 y $16 \%$ en el 2015 , mientras que el bosque de baja densidad incremento en $0.7 \%$ y la vegetación anegada aumento su superficie en $0.35 \%$ durante este periodo (mapa 2 y mapa 3 ). Estas condiciones corroboran la tendencia de recuperación que presenta la cobertura boscosa en Costa Rica, la cual ha permitido al país remontar sus altas tasas de desforestación y ser el único país en condiciones tropicales que se presenta un proceso de recuperación como lo muestran estudios más recientes del Fondo de Financiamiento Forestal de Costa Rica (FONAFIFO), 2012).

Esta recuperación a nivel nacional de acuerdo al Estado de la Nación (sf), es producto de la combinación de factores en los que se destaca la disminución de mercados internacionales de carne y el impacto positivo del pago de servicios ambientales (PSA), las cuales representaron un 18\% de la cobertura forestal en el periodo 1997 - 2005. No obstante, aunque se evidencia el aumento en la superficie de los bosques secundarios, la tala con fines agrícolas es continúa ya que algunos agricultores evitan la regeneración del bosque porque no desean perder la oportunidad de utilizar su tierra para la agricultura (FAO, 2016). De acuerdo con Morera y Sandoval (2013), las condiciones económicas y ecológicas, durante los últimos años, han transformando el comportamiento histórico de la cobertura boscosa del país, lo cual ha revertido las tasas de desforestación, hasta incrementar sus superficies forestales. El proceso anterior ha favorecido el surgimiento de paisajes salpicados con una alta presencia de conectividad ecológica (más de 60\% en cobertura boscosa), donde se superan algunos limitantes de fragmentación.

Sin embargo, las interrogantes que emergen son, valorar sí la restauración es igual para todos los ecosistemas naturales y cuál es la calidad de estos ecosistemas restaurados, (Morera y Sandoval, 2016). Si bien los estudios realizados por Calvo, Watson, Bolaños, Quesada, Sánchez, Gonzáles y Ramírez (1999) muestran la tendencia hacia la recuperación de la 
cobertura natural en el país, existen coberturas de uso de la tierra como los manglares que evidencian el decrecimiento de su superficie para el periodo 2000 - 2015, donde se reflejó una reducción de su superficie del 0.02\% (682 ha) (Gráfico 1). Asociado a los procesos de cambios de uso de la tierra por actividades antrópicas como la construcción de puertos, hoteles y tala de la cobertura natural para su transformación a usos agrícolas y pastizales generan daños irreversibles en estos ecosistemas (Zamora y Cortés, 2009).

Grafico 1. Costa Rica: Cobertura natural del uso de la tierra periodo $2000-2015$

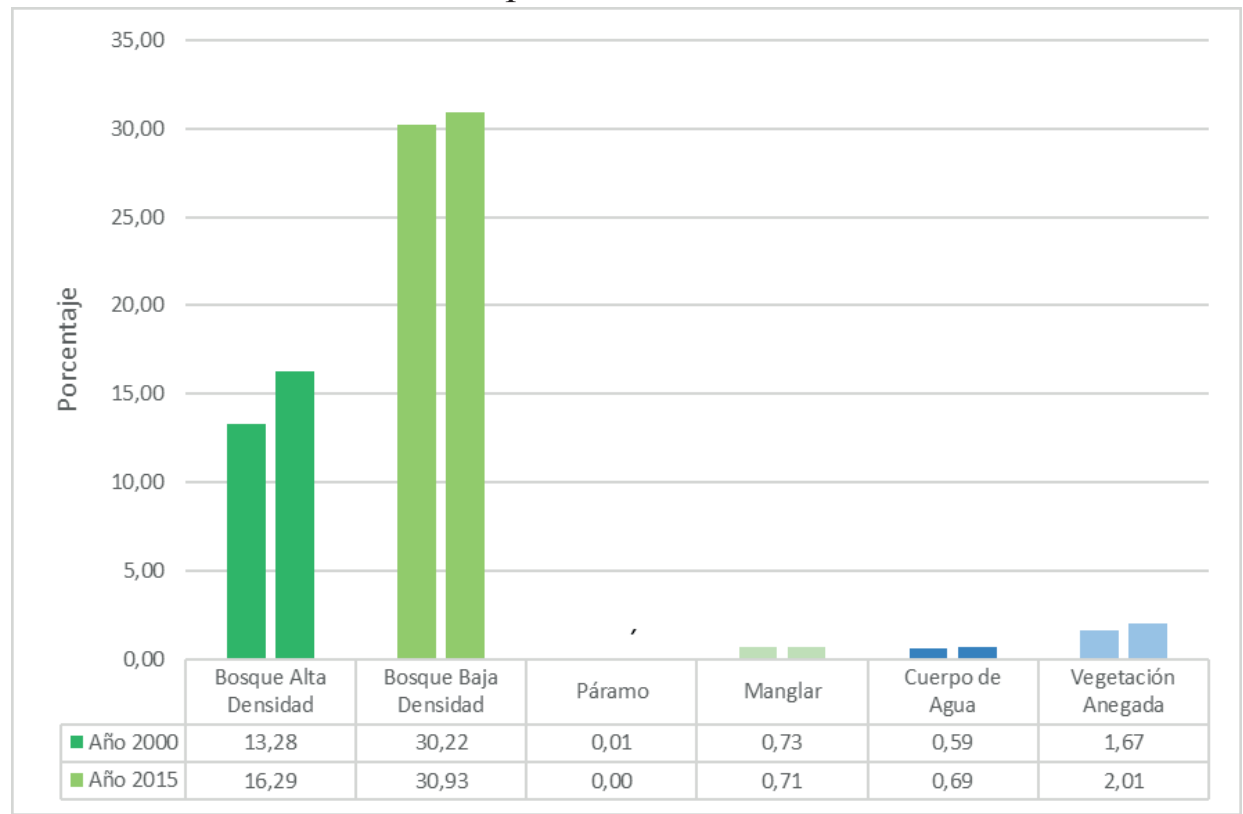

Fuente: Elaboración propia a partir de coberturas de uso de la tierra 2000 y 2015. 
Carlos Morera-Beita - Luis Fernando Sandoval-Murillo Fragmentation and connectivity of the natural cover at county level in Costa Rica, during 2000 and 2015 years

Mapa 2. Costa Rica: Uso de la tierra por cantones año 2000

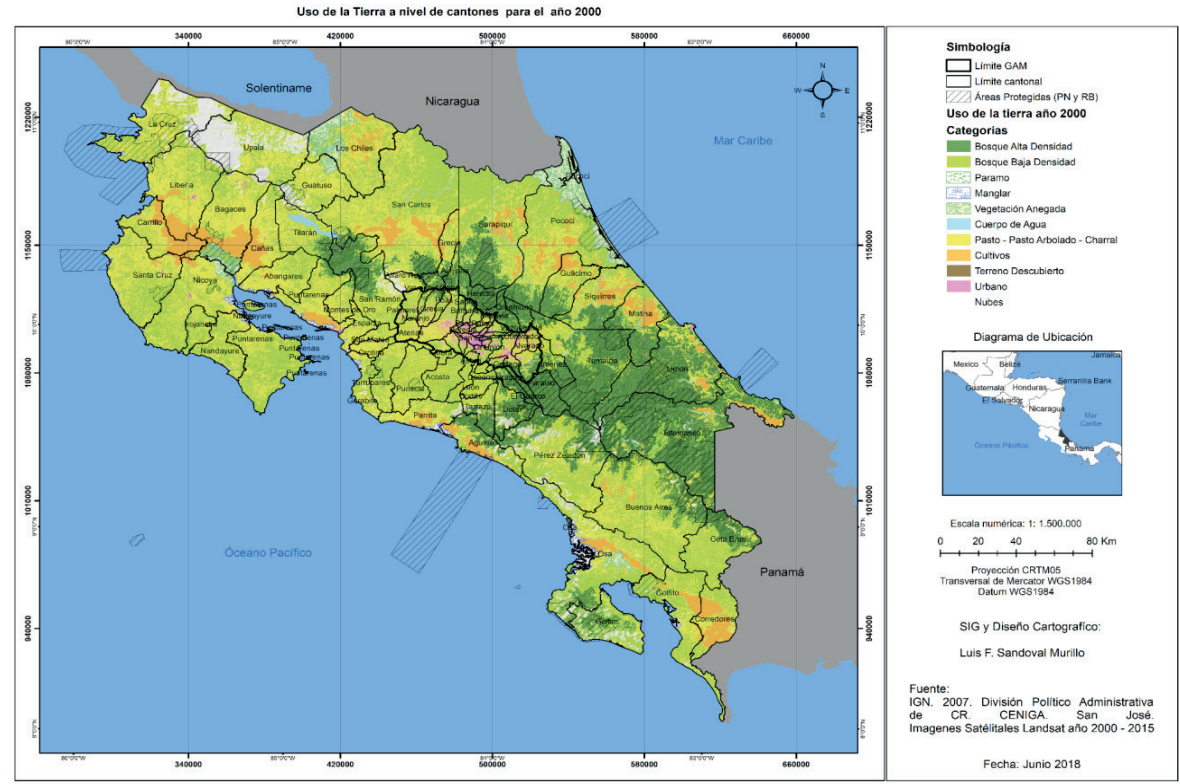

Mapa 3. Costa Rica: Uso de la tierra por cantones año 2015

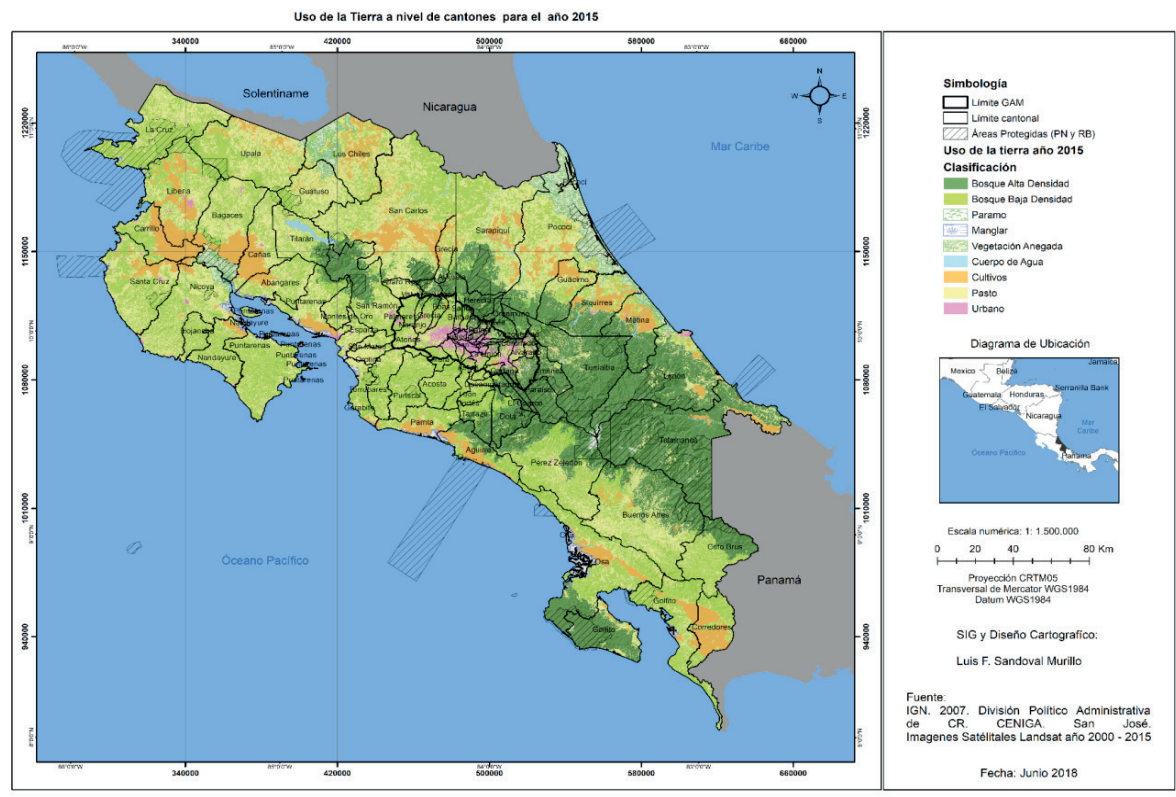




\section{Aplicabilidad de índices biométricos por cantón}

Los resultados de la ecuación del Índice de Fragmentación/ Conectividad para cada uno de los cantones muestran que a medida que aumenta el valor se incrementa el grado de fragmentación y decrece la conectividad de las coberturas naturales. En cantones con niveles mayores de 15.01 (Alta Fragmentación) donde se ubican 24 (29.6\%) de los 81 cantones con cobertura natural escasa en el año 2000, dominados por dinámicas rurales son: Orotina, Limón, Grecia, Alajuela, Sarapiquí, Nicoya, Pococí, San Ramón, Puntarenas, Guatuso, Cañas. Carrillo, Talamanca, Los Chiles, Pérez Zeledón, Osa, Golfito, Santa Cruz, Liberia, Bagaces, Buenos Aires, San Carlos, Upala y La Cruz (Mapas 4 y 5). Para el año 2015, la categoría de alta fragmentación se reduce y solo 8 (9.9\%) cantones presentan esta característica: Los Chiles, Osa, Bagaces, Golfito, Pococí, Guatuso, San José, San Carlos y Buenos Aires (Anexo 1). Destaca que para el 2015 se mantienen un número significativo $(87.5 \%)$ de los cantones que estaban dentro de esta categoría durante el 2000 con dinámicas rurales donde predomina actividades asociadas a monocultivos y pastizales, sin embargo, se presenta un caso urbano, que es el cantón de San José, donde los procesos urbanos se intensifican reduciendo los escasos ecosistemas naturales de relicto.

En el año 2000, los siguientes 32 (39,5 \%) cantones: Jiménez, Poás, El Guarco, Mora, Tarrazú, San Mateo, Heredia, Vázquez de Coronado, Dota, Coto Brus, Valverde Vega, Oreamuno, Turrubares, Aguirre, Nandayure, Alvarado, Matina. Garabito, Paraíso, Cartago, Corredores, Montes de Oro, Siquirres, Puriscal, Guácimo, Esparza, Alfaro Ruiz, Atenas, Abandares, Parrita, Tilarán y Turrialba; presentaron una fragmentación moderada, siendo todos los cantones de tipo rurales con excepción de Cartago y Heredia (Anexo 2). Para el 2015, los siguientes cantones presentaron una fragmentación moderada: El Guarco, Nandayure, Escazú, Tibás, Desamparados, Aguirre, Tibás, Desamparados, Aguirre, Esparza, Alajuela, Coto Brus, Santo Domingo, Curridabat, Grecia, Guácimo, Vázquez de Coronado, Corredores, Talamanca, San Ramón, Alfaro Ruiz, Alvarado, Limón, Cañas, Orotina, Matina, Puntarenas, Liberia, Tilarán, Paraíso, Turrialba, Santa Cruz, Siquirres, La Cruz, Oreamuno, Cartago, Upala, Pérez Zeledón, Nicoya y Sarapiquí, siendo $47 \%$ (38 cantones), una tendencia que aumenta en 15 cantones (47\%) durante estos quince años de estudio. 
La categoría de baja fragmentación con valores entre 0.00 y 3.00 para el año 2000 incluye a $25(31 \%)$ de los cantones de: Acosta, Alajuelita, Aserrí, Barva, Belén, Curridabat, Desamparados, Escazú, Flores, Goicochea, Hojancha, La Unión, León Cortés, Montes de Oca, Moravia, Naranjo, Palmares, San Isidro, San José, San Pablo, San Rafael, Santa Ana, Santa Bárbara, santo Domingo y Tibás, siendo la mayoría espacios dominados por dinámicas urbanas (Anexo 3). Para el 2015, el número de cantones se incrementa a 33 (41\%) siendo estos: Acosta, Alajuelita, Aserrí, Barva, Belén, Dota, Flores, Garabito, Goicochea, Heredia, Hojancha, Jiménez, La Unión, León Cortés, Montes de Oca, Montes de Oro, Mora, Moravia, Naranjo, Palmares, Parrita, Poás, Puriscal, San Isidro, San Mateo, San Pablo, San Rafael, Santa Ana, Santa Bárbara, Santo Domingo, Tarrazú, Turrubares, Tibás y Valverde Vega. La tendencia en incrementar el número de cantones es un indicador de reducción de los procesos de fragmentación en el país, lo cual tiene su asidero en espacios urbanos, donde el impacto antrópico sobre el paisaje es menor comparado con espacios rurales donde dominan algunos monocultivos como la piña y el banano con una concentración espacial mayor.

\section{Incremento y reducción en el índice de fragmentación-conectivi- dad 2000-2015}

Comparando los resultados del 2000 y del 2015 se identifican que seis $(7.4 \%)$, de los cuales todos son cantones urbanos como: Curridabat, Desamparados, Escazú, Santo Domingo y Tibás, pasaron de una baja fragmentación a una moderada, mientras que San José fue el único cantón que paso de baja fragmentación a alta. Lo anterior se relaciona con los acelerados procesos de urbanización que presentan estos cantones, los cuales generan cambios en su cobertura eliminando las condiciones naturales para ser remplazadas por actividades urbanas(Tabla 4).

Por otro lado, ocho cantones mantuvieron sus procesos de alta fragmentación: Pococí, Guatuso, Los Chiles, Osa, Golfito, Bagaces, Buenos Aires y San Carlos, caracterizado por la presencia del cultivo de piña y palma africana, característica que se mantuvo durante los quince años de estudio. Mientras 18 (22.2\%) cantones mantienen su condición de fragmentación moderada siendo estos: El Guarco, Vázquez de Coronado, Coto Brus, Oreamuno, Aguirre, Nandayure, Alvarado, Matina, Paraíso, Cartago, 
Corredores, Siquirres, Guácimo, Esparza, Alfaro Ruiz, Abangares, Tilarán y Turrialba, los cuales combinan patrones de cantones rurales, urbanos y peri-urbanos. Asimismo, 19 (23.5 \%) cantones mantuvieron la característica de baja fragmentación: El Guarco, Vázquez de Coronado, Coto Brus, Oreamuno, Aguirre, Nandayure, Alvarado, Matina, Paraíso, Cartago, Corredores, Siquirres, Guácimo, Esparza, Alfaro Ruiz, Abangares, Tilarán y Turrialba, que al igual que la anterior categoría combinan diferentes procesos tanto urbanos como rurales.

En cuanto a los cantones que redujeron sus niveles de fragmentación durante el periodo de estudio, $15(18.5 \%)$ pasaron de alta a moderada fragmentación siendo estos: Orotina, Limón, Grecia, Alajuela, Sarapiquí, Nicoya, San Ramón, Puntarenas, Cañas, Talamanca, Pérez Zeledón, Santa Cruz, Upala y La Cruz, caracterizados por ser espacios de dominio de procesos rurales. Únicamente, el cantón de Carrillo pasó de alta fragmentación a baja fragmentación, lo cual se puede deber al desarrollo turístico que valora más el paisaje natural, en relación con el dominio de actividades agro-productivas como ocurría anteriormente. En condición similar, los siguientes 14 (7.3 \%) cantones: Jiménez, Poás, Mora, Tarrazú, San Mateo, Heredia, Dota, Valverde Vega, Turrubares, Garabito, Montes de Oro, Puriscal, Atenas y Parrita se trasformaron de moderada a baja fragmentación. 
Carlos Morera-Beita - Luis Fernando Sandoval-Murillo Fragmentation and connectivity of the natural cover at county level in Costa Rica, during 2000 and 2015 years

Mapa 4. Costa Rica. Índice de Fragmentación/Conectividad a nivel de cantones para el año 2000

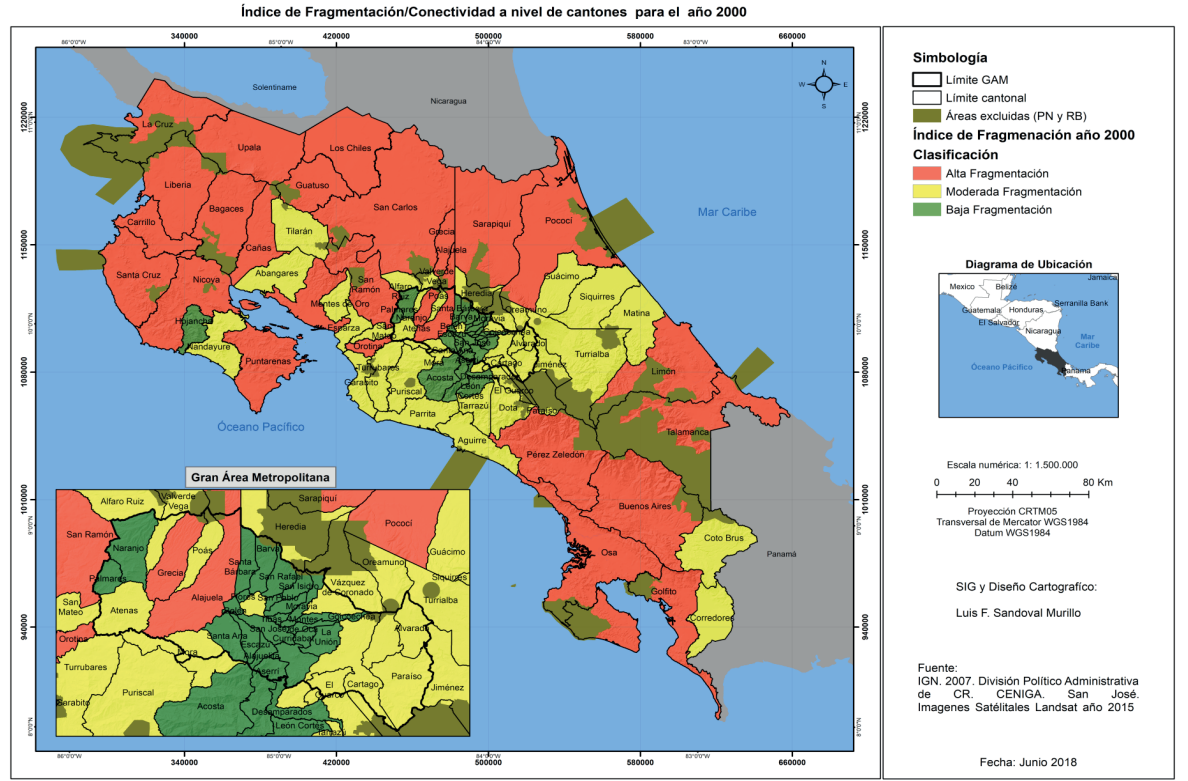

Mapa 5. Costa Rica. Índice de Fragmentación/Conectividad a nivel de cantones para el año 2015

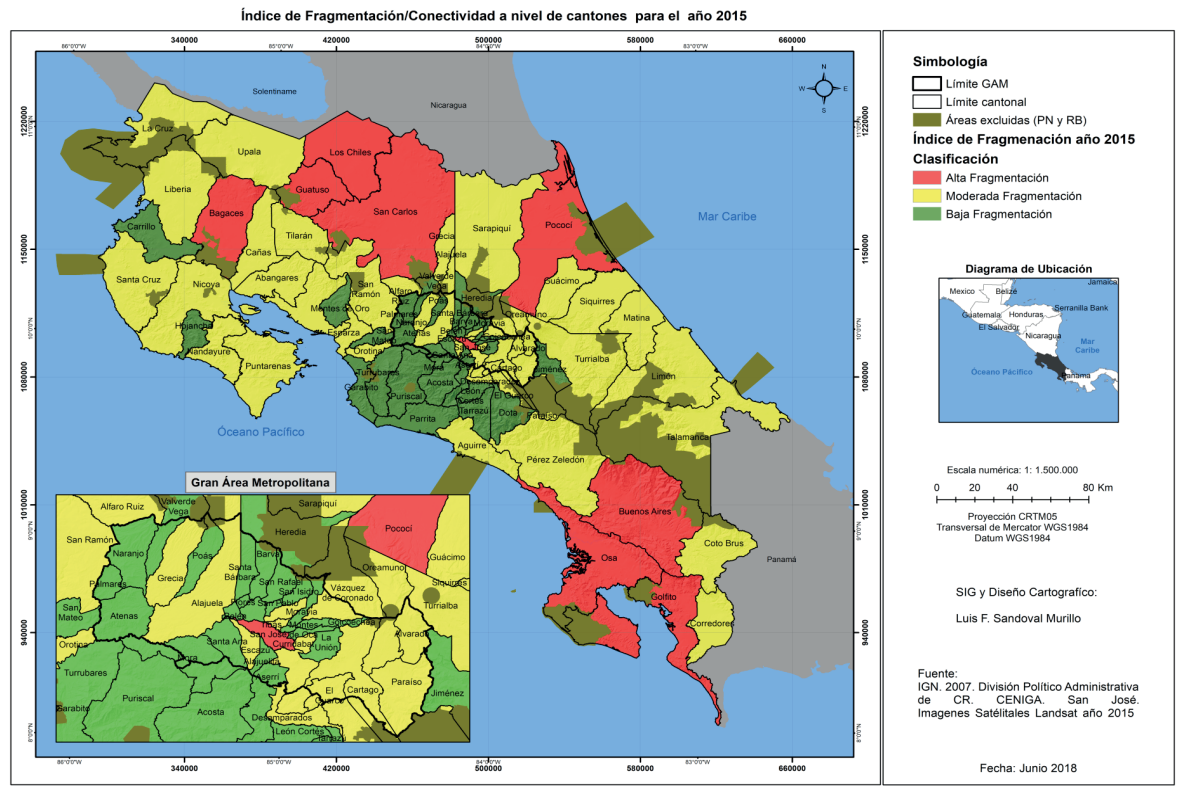

50 Revista Geográfica de América Central. No 61E (4) Especial e-ISSN 2215-2563 / Julio-diciembre 2018 
Tabla 4. Transformaciones del índice de fragmentación según cantones periodo 2000 - 2015

\begin{tabular}{|c|c|}
\hline $\begin{array}{l}\text { Cambios en el índice de } \\
\text { fragmentación }\end{array}$ & Cantones \\
\hline $\begin{array}{l}\text { Alta Fragmentación - Moderada } \\
\text { Fragmentación }\end{array}$ & $\begin{array}{l}\text { Orotina, Limón, Grecia, Alajuela, Sarapiquí, } \\
\text { Nicoya, San Ramón, Puntarenas, Cañas, } \\
\text { Talamanca, Pérez Zeledón, Santa Cruz, } \\
\text { Moderada, Upala y La Cruz. }\end{array}$ \\
\hline Se mantuvo en Alta fragmentación & $\begin{array}{l}\text { Pococí, Guatuso, Los Chiles, Osa, Golfito, } \\
\text { Bagaces, Buenos Aires y San Carlos. }\end{array}$ \\
\hline $\begin{array}{l}\text { Alta fragmentación - Baja } \\
\text { fragmentación }\end{array}$ & Carrillo \\
\hline $\begin{array}{l}\text { Moderada fragmentación - Baja } \\
\text { fragmentación }\end{array}$ & $\begin{array}{l}\text { Jiménez, Poás, Mora, Tarrazú, San Mateo, } \\
\text { Heredia, Dota, Valverde Vega, Turrubares, } \\
\text { Garabito, Montes de Oro, Puriscal, Atenas y } \\
\text { Parrita. }\end{array}$ \\
\hline Se mantiene en moderada & $\begin{array}{l}\text { El Guarco, Vázquez de Coronado, Coto Brus, } \\
\text { Oreamuno, Aguirre, Nandayure, Alvarado, } \\
\text { Matina, Paraíso, Cartago, Corredores, Siquirres, } \\
\text { Guácimo, Esparza, Alfaro Ruiz, Abangares, } \\
\text { Tilarán y Turrialba. }\end{array}$ \\
\hline $\begin{array}{l}\text { Se mantiene en Baja } \\
\text { Fragmentación }\end{array}$ & $\begin{array}{l}\text { Acosta, Alajuelita, Aserrí, Barva, Belén, Flores, } \\
\text { Goicoechea, Hojancha, La Unión, León Cortés, } \\
\text { Montes de Oca, Moravia, Naranjo, Palmares, } \\
\text { San Isidro, San Pablo, San Rafael, Santa Ana y } \\
\text { Santa Bárbara. }\end{array}$ \\
\hline $\begin{array}{l}\text { Baja Fragmentación - Moderada } \\
\text { Fragmentación }\end{array}$ & $\begin{array}{l}\text { Curridabat, Desamparados, Escazú, Santo } \\
\text { Domingo y Tibás. }\end{array}$ \\
\hline $\begin{array}{l}\text { Baja Fragmentación - Alta } \\
\text { Fragmentación }\end{array}$ & San José \\
\hline
\end{tabular}

De acuerdo con lo expresado por Gurrutxaga y Lozano (2006) las principales tendencias que se generan en las dinámicas del paisaje rural en los últimos años son la reducción y fragmentación de hábitats naturales y la homogenización de los paisajes agro-pastoriles. Sin embargo, en el caso de Costa Rica, estos procesos se combinan con acelerados procesos de urbanización y expansión de monocultivos, así con el desarrollo concentrado de la actividad turística en espacios costeros. La tendencia se explica por el creciente desarrollo de las actividades como monocultivos, por ejemplo, 
el cultivo de la piña, y de acuerdo con lo expresado por Valverde, Porras y Jiménez (2016) la expansión significativa de la producción piñera en Costa Rica se concentra en las siguientes regiones: Pacífico Sur, Caribe Norte y Zona Norte. Dicha expansión ha conducido a una modificación de realidades socio-ambientales: cambio paisajístico donde se instauran extensas regiones de un monocultivo. Generando cambios en el uso del suelo de miles de hectáreas que antes estaban destinadas a la protección del bosque y de mantos acuíferos. Asimismo, ha existido una invasión de las áreas de protección de ríos y manantiales (Acuña, 2006)

\section{Conclusiones}

En general, este artículo evidencia la recuperación de la cobertura natural durante las últimas décadas. Sin embargo, algunos cantones urbanos presentan un incremento de los procesos de fragmentación como: Curridabat, Desamparados, Escazú, Santo Domingo, Tibás y San José. Mientras otros cantones rurales como Pococí Guatuso, Los Chiles, Osa, Golfito, Bagaces, Buenos Aires y San Carlos, mantienen sus altos grados de fragmentación relacionado con la expansión de los monocultivos, especialmente, piña y palma africana.

La dinámica territorial asociada a las condiciones económicas en los últimos años ha generado transformaciones significativas en la estructura del paisaje natural, siendo los cantones con tendencias más urbanas los que presentaron transformaciones de índices de fragmentación/conectividad más negativa, lo cuales se localizan el Gran Área Metropolitana (GAM) (Mapa 6), los cuales se caracterizan por una concentración de actividades urbanas y a la eliminación de la coberturas naturales, debido a factores de crecimiento urbano. Los cambios de la sociedad costarricense de una sociedad rural a una urbana ha implicado dinámicas ambientales y sociales específicas que concentran los efectos antrópicos en los cantones que conforman el GAM. Además, continuando con este análisis comparativo entre 2000 y 2015, se identifica que fuera del GAM, dos cantones presentan patrones diferenciales. Por un lado, está el caso de Siquirres que mantuvo condiciones similares durante los dos años estudiados, mientras Buenos Aires, presentó condiciones negativas, relacionado con expansión del cultivo de piña. 
Carlos Morera-Beita - Luis Fernando Sandoval-Murillo

Fragmentación y conectividad de la cobertura natural a nivel cantonal en Costa Rica durante los años 2000 y 2015

Mapa 6. Costa Rica: Cambios en el Índice de Fragmentación/ Conectividad a nivel de cantones para el año 2000 - 2015

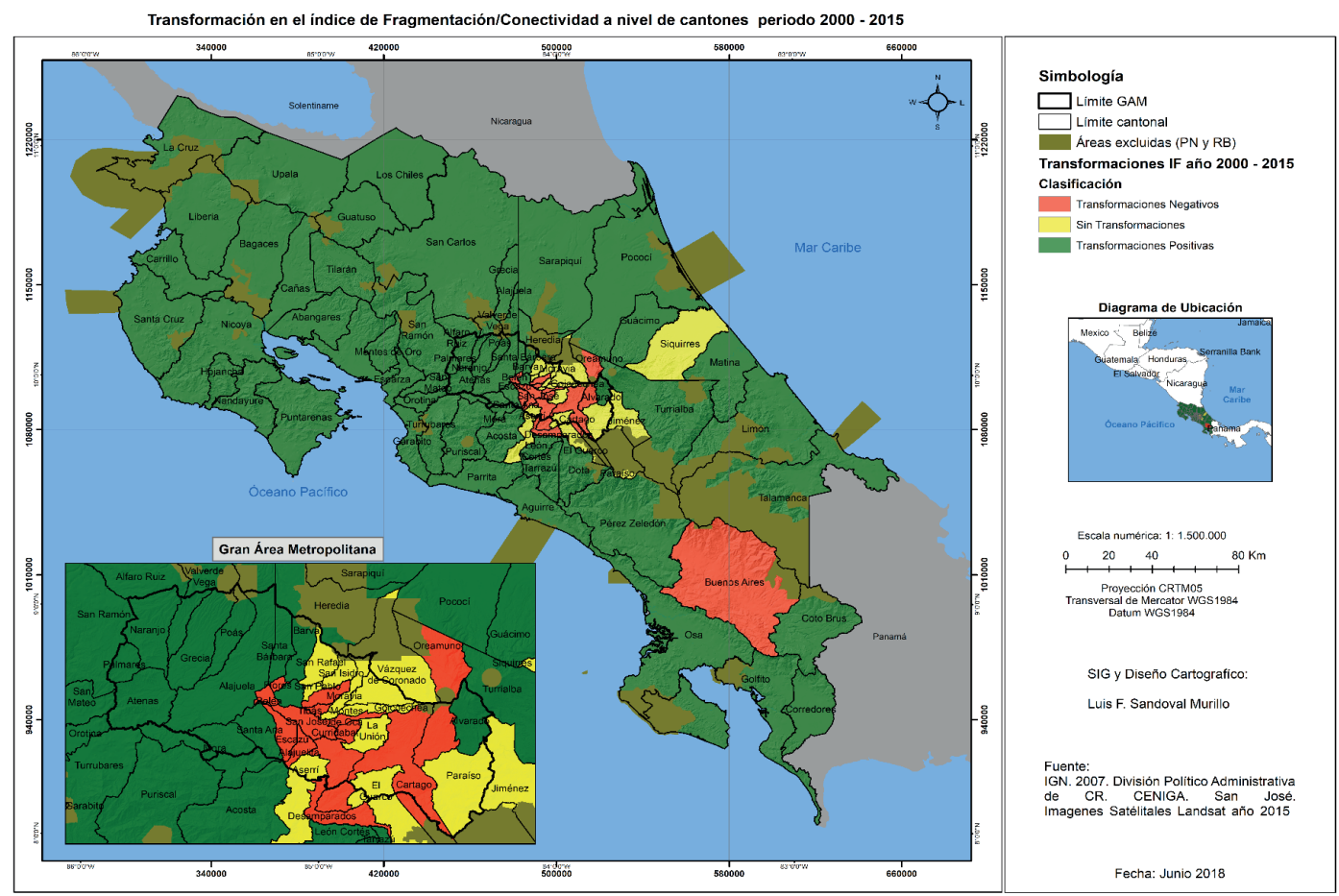

\section{Referencias}

Acuña, G. (2006). Producción de piña en Caribe y Pacífico Sur de Costa Rica. Ambientico, Revista mensual sobre la actualidad ambiental, 158, 1-3. Heredia. Costa Rica, ISSN 1409-214X

Ambrosio, G. González, J. y Arévalo, V. (s.f.). Corrección radiométrica y geométrica de imágenes para la detección de cambios en una serie temporal. Dpto. Ingeniería de Sistemas y Automática. Universidad de Málaga.

Calvo, A. y Ortiz, E. (2011). Fragmentación de la cobertura forestal en Costa Rica durante los periodos 1997-2000 y 2000-2005. En: Revista Forestal Mesoamericana Kurù, 9(22), 10-21.

Calvo, J., Watson V., Bolaños, R., Quesada C., Sánchez, A, Gonzáles, P. y Ramírez, J. (1999). Estudio de la cobertura forestal de Costa Rica empleando imágenes Landsat 1986/1987 y 1996/1997. Documento 
presentado en el marco del XI Congreso Agronómico Nacional y de Recursos Naturales. San José, Costa Rica.

Fondo de Financiamiento Forestal de Costa Rica (FONAFIFO). (2012). Estudio de la Cobertura Forestal de Costa Rica 2009-2010. En: htpp: minae.go.cr/recursos/ documentos/coberturas-forestal/estudiocobertura-forestal-FONAFIFO-marzo-2012.pdf.

FAO. (2016). La cubierta forestal se ha ampliado producto de prácticas agrícolas más sostenibles, la reversión de la deforestación y a los estrictos controles legales implementados. Organización de las Naciones Unidas para la Alimentación y la Agricultura.

Gurrutxaga, M. y Lozano, P. (2006). Efectos de la fragmentación de hábitats y pérdida de conectividad ecológica dentro de la dinámica territorial. Departamento de Geografía, Prehistoria y Arqueología. Universidad del País Vasco. Polígonos. Revista de Geografía, 16, 35-54 Morera, C. (2010). Estructura del Paisaje y Desarrollo Turístico en la Fila Brunqueña, Costa Rica. En: Revista Geográfica de América Central, 44, 91-108.

Morera, C. y Sandoval, L. (2013). Los procesos de fragmentación y la conectividad forestal en Costa Rica: Dos casos de estudios. En: Geografía, Paisaje y Conservación. ECG - UNA. (agregar número y páginas)

Morera, C. y Sandoval, L. (2015). Aplicabilidad de indicadores de estructura de paisaje para evaluar transformaciones en escenarios tropicales. En: Métodos y Técnicas Geográficas Aplicadas al Ambiente: Una Visión Latinoamericana. Universidad Autónoma de San Luis Potosí, México. EUNA, Heredia.

Morera, C. \& Sandoval, L. F. (2016). Evaluación de la cobertura boscosa en Costa Rica: un análisis a nivel de áreas de conservación en el año 2000. En Revista Geográfica de América Central, 56(2), 163-182.

Liu, X., Li, X., Chen, Y., Tan, Z., Li, S. \& Ai, B. (2010). A new landscape index for quantifying urban expansion using multi-temporal remotely sensed data. In Landscape Ecology, 25, 671-682. https://doi. org/10.1007/s10980-010-9454-5

Priego, A., Bocco, G., Mendoza, M. \& Garrido, A. (2008). Propuesta para la generación semi-automatizada de unidades de paisajes. Secretaria de Medio Ambiente y Recursos Naturales Instituto Nacional de 
Ecología Centro de Investigaciones en Geografía Ambiental Universidad Nacional Autónoma de México. Secretaria de Medio Ambiente y Recursos Naturales (Semarnat México.), México D.F.

Salas, S. y Durán, A. (2015). Caracterización del uso del suelo en las principales áreas agrícolas de la Gran Área Metropolitana (GAM) de Costa Rica. Agronomía Costarricense, 39(1). San Pedro de Montes de Oca.

Sánchez, A., Foley, S., Hamilton, S., Calvo, C., Arroyo, P. y Jiménez, V. (2002). Estudio de Cobertura Forestal de Costa Rica imágenes Landsat TM/ para el año 2000. Centro Científico Tropical. San José, Costa Rica.

Vargas, G. (2008). Fragmentación y conectividad de ecosistemas en el sector del proyecto geotérmico Miravalles y sus alrededores. 19752007. En Revista Reflexiones, 87(2), 9-38.

Valverde, K., Porras, M. y Jiménez, A. (2016). La expansión por omisión: Territorios piñeros en los cantones Los Chiles, Upala y Guatuso, Costa Rica (2004 -2015. Vigésimo Segundo informe estado de la nación en desarrollo humano sostenible. San José. Costa Rica.

Veldkamp, A. \& Fresco, L. O. (1996). CLUE-CR: an integrated multiscale model to simulate land use change scenarios in Costa Rica. Ecological modelling, 91(1), 231-248.

Zamora, P. y Cortés, J. (2009). Los manglares de Costa Rica: el Pacífico Norte. Revista Biología Tropical, 57(3), 473-488. ISSN-0034-7744

\section{Anexos}

Anexo 1. Alta fragmentación por cantones para 2000 y 2015

\begin{tabular}{|l|c|c|c|c|c|}
\hline \multicolumn{7}{|c|}{ Alta fragmentación año 2000 } \\
\hline Cantón & $\begin{array}{c}\text { Área del } \\
\text { Cantón }\end{array}$ & $\begin{array}{c}\text { Cobertura } \\
\text { Natural }\end{array}$ & $\begin{array}{c}\text { Número de } \\
\text { Fragmentos }\end{array}$ & $\begin{array}{c}\text { Vecino más } \\
\text { Cercano }\end{array}$ & $\begin{array}{c}\text { Índice de } \\
\text { Fragmentación }\end{array}$ \\
\hline Orotina & 14559.65 & 3074.59 & 293 & 1.16 & 16.05 \\
\hline Limón & 176767.30 & 99946.70 & 1135 & 0.85 & 16.97 \\
\hline Grecia & 39734.22 & 15957.65 & 705 & 0.98 & 17.26 \\
\hline Alajuela & 39143.60 & 15413.69 & 697 & 1.02 & 18.04 \\
\hline Sarapiquí & 214551.94 & 134350.28 & 1428 & 0.82 & 18.68 \\
\hline Nicoya & 133925.18 & 63725.59 & 1175 & 0.88 & 21.75 \\
\hline
\end{tabular}


Carlos Morera-Beita - Luis Fernando Sandoval-Murillo Fragmentation and connectivity of the natural cover at county level in Costa Rica, during 2000 and 2015 years

\begin{tabular}{|l|r|r|r|r|r|}
\hline \multicolumn{1}{|c|}{ Cantón } & $\begin{array}{c}\text { Área del } \\
\text { Cantón }\end{array}$ & $\begin{array}{c}\text { Cobertura } \\
\text { Natural }\end{array}$ & $\begin{array}{c}\text { Número de } \\
\text { Fragmentos }\end{array}$ & $\begin{array}{c}\text { Vecino más } \\
\text { Cercano }\end{array}$ & $\begin{array}{c}\text { Índice de } \\
\text { Fragmentación }\end{array}$ \\
\hline Pococí & 238729.19 & 135166.26 & 1570 & 0.79 & 21.82 \\
\hline San Ramón & 102072.92 & 59697.48 & 1340 & 0.96 & 21.91 \\
\hline Puntarenas & 181929.30 & 99921.02 & 1472 & 0.88 & 23.69 \\
\hline Guatuso & 75972.21 & 27098.81 & 924 & 0.95 & 24.66 \\
\hline Cañas & 69082.22 & 14348.35 & 580 & 0.91 & 25.46 \\
\hline Carrillo & 59940.75 & 12307.47 & 644 & 0.82 & 25.63 \\
\hline Talamanca & 281639.91 & 94532.64 & 939 & 0.92 & 25.65 \\
\hline Los Chiles & 133713.28 & 67465.57 & 1448 & 0.93 & 26.79 \\
\hline Pérez Zeledón & 190091.42 & 103264.41 & 1694 & 0.88 & 27.40 \\
\hline Osa & 189016.51 & 100732.89 & 1767 & 0.83 & 27.48 \\
\hline Golfito & 174995.00 & 76383.99 & 1463 & 0.85 & 28.51 \\
\hline Santa Cruz & 132084.12 & 56936.24 & 1351 & 0.94 & 29.55 \\
\hline Liberia & 144306.62 & 38798.94 & 1033 & 0.87 & 33.56 \\
\hline Bagaces & 127848.72 & 25776.06 & 1150 & 0.82 & 47.03 \\
\hline Buenos Aires & 238324.60 & 125936.99 & 2771 & 0.90 & 47.16 \\
\hline San Carlos & 335067.58 & 163081.89 & 2788 & 0.83 & 47.48 \\
\hline Upala & 158328.82 & 41078.85 & 1563 & 0.89 & 53.64 \\
\hline La Cruz & 138745.41 & 17615.32 & 839 & 0.87 & 57.27 \\
\hline & & & & \\
\hline
\end{tabular}

Alta fragmentación año 2015

\begin{tabular}{|l|r|r|r|r|r|}
\hline \multicolumn{1}{|c|}{ Cantón } & $\begin{array}{c}\text { Área del } \\
\text { Cantón }\end{array}$ & $\begin{array}{c}\text { Cobertura } \\
\text { Natural }\end{array}$ & $\begin{array}{c}\text { Numero de } \\
\text { Fragmentos }\end{array}$ & $\begin{array}{c}\text { Vecino más } \\
\text { Cercano }\end{array}$ & $\begin{array}{c}\text { Índice de } \\
\text { Fragmentación }\end{array}$ \\
\hline Los Chiles & 133713.28 & 59018.29 & 706 & 0.97 & 15.49 \\
\hline Osa & 189016.51 & 118380.21 & 1606 & 0.64 & 16.45 \\
\hline Bagaces & 127848.72 & 38721.98 & 678 & 0.75 & 16.77 \\
\hline Golfito & 174995.00 & 87090.73 & 1357 & 0.69 & 18.82 \\
\hline Pococí & 238729.19 & 110323.04 & 1061 & 0.84 & 19.36 \\
\hline Guatuso & 75972.21 & 23720.02 & 612 & 1.03 & 20.25 \\
\hline San José & 4474.38 & 168.81 & 126 & 0.67 & 22.49 \\
\hline San Carlos & 335067.58 & 126030.77 & 1841 & 0.91 & 44.54 \\
\hline Buenos Aires & 238324.60 & 128840.93 & 4272 & 0.79 & 62.15 \\
\hline
\end{tabular}

Fuente: Elaboración propia 
Carlos Morera-Beita - Luis Fernando Sandoval-Murillo

Fragmentación y conectividad de la cobertura natural a nivel cantonal en Costa Rica durante los años 2000 y 2015

Anexo 2. Fragmentación Moderada por cantones para 2000 y 2015

\begin{tabular}{|c|c|c|c|c|c|}
\hline \multicolumn{6}{|c|}{ Moderada fragmentación año 2000} \\
\hline Cantón & $\begin{array}{c}\text { Área } \\
\text { Cantón }\end{array}$ & $\begin{array}{c}\text { Cobertura } \\
\text { Natural }\end{array}$ & $\begin{array}{l}\text { Numero de } \\
\text { Fragmentos }\end{array}$ & $\begin{array}{c}\text { Vecino más } \\
\text { Cercano }\end{array}$ & $\begin{array}{c}\text { Índice de } \\
\text { Fragmentación }\end{array}$ \\
\hline Jiménez & 25068.48 & 15375.25 & 205 & 0.93 & 3.10 \\
\hline Poás & 7441.07 & 3478.32 & 146 & 1.02 & 3.18 \\
\hline El Guarco & 17285.46 & 9737.35 & 198 & 0.99 & 3.48 \\
\hline Mora & 16364.88 & 8351.73 & 192 & 0.95 & 3.56 \\
\hline Tarrazú & 29272.64 & 19899.69 & 298 & 0.88 & 3.87 \\
\hline San Mateo & 12405.39 & 4652.43 & 151 & 1.00 & 4.02 \\
\hline Heredia & 28291.82 & 9928.80 & 185 & 0.81 & 4.26 \\
\hline $\begin{array}{l}\text { Vázquez de } \\
\text { Coronado }\end{array}$ & 22390.71 & 11405.52 & 278 & 0.91 & 4.99 \\
\hline Dota & 40395.32 & 26634.35 & 370 & 0.91 & 5.11 \\
\hline Coto Brus & 94267.04 & 62957.29 & 548 & 0.76 & 6.20 \\
\hline Valverde Vega & 13685.42 & 6135.05 & 288 & 0.99 & 6.35 \\
\hline Oreamuno & 20189.74 & 8671.04 & 307 & 0.90 & 6.45 \\
\hline Turrubares & 41582.03 & 21290.01 & 373 & 0.91 & 6.63 \\
\hline Aguirre & 55673.49 & 27970.81 & 397 & 0.86 & 6.80 \\
\hline Nandayure & 56540.07 & 30815.07 & 463 & 0.91 & 7.72 \\
\hline Alvarado & 7959.31 & 2061.34 & 197 & 1.05 & 8.02 \\
\hline Matina & 77098.21 & 44774.61 & 637 & 0.84 & 9.17 \\
\hline Garabito & 31331.12 & 11419.52 & 329 & 1.03 & 9.29 \\
\hline Paraíso & 47737.64 & 12849.32 & 264 & 0.97 & 9.51 \\
\hline Cartago & 27765.05 & 10901.38 & 360 & 1.04 & 9.52 \\
\hline Corredores & 62467.34 & 18337.84 & 426 & 0.72 & 10.38 \\
\hline $\begin{array}{l}\text { Montes de } \\
\text { Oro }\end{array}$ & 24806.23 & 10055.27 & 403 & 1.05 & 10.47 \\
\hline Siquirres & 85481.31 & 45754.80 & 696 & 0.83 & 10.81 \\
\hline Puriscal & 55607.57 & 24906.68 & 584 & 0.92 & 12.05 \\
\hline Guácimo & 58031.35 & 32423.13 & 732 & 0.95 & 12.43 \\
\hline Esparza & 21807.08 & 6397.83 & 353 & 1.15 & 13.82 \\
\hline Alfaro Ruiz & 15772.14 & 3800.38 & 309 & 1.09 & 13.95 \\
\hline Atenas & 12646.65 & 3510.96 & 323 & 1.20 & 13.98 \\
\hline Abangares & 64453.77 & 26214.30 & 609 & 0.94 & 14.10 \\
\hline Parrita & 47737.24 & 15573.64 & 468 & 1.00 & 14.34 \\
\hline
\end{tabular}


Carlos Morera-Beita - Luis Fernando Sandoval-Murillo Fragmentation and connectivity of the natural cover at county level in Costa Rica, during 2000 and 2015 years

\begin{tabular}{|l|r|r|r|r|r|}
\hline Tilarán & 66755.25 & 28369.42 & 630 & 1.01 & 15.03 \\
\hline Turrialba & 158749.68 & 96723.63 & 1227 & 0.77 & 15.59 \\
\hline
\end{tabular}

\section{Moderada fragmentación año 2015}

\begin{tabular}{|c|c|c|c|c|c|}
\hline Cantón & Área Cantón & $\begin{array}{c}\text { Cobertura } \\
\text { Natural }\end{array}$ & $\begin{array}{l}\text { Numero de } \\
\text { Fragmentos }\end{array}$ & $\begin{array}{c}\text { Vecino más } \\
\text { Cercano }\end{array}$ & $\begin{array}{c}\text { Índice de } \\
\text { Fragmentación }\end{array}$ \\
\hline EI Guarco & 17285.46 & 10274.69 & 238 & 0.77 & 3.06 \\
\hline Nandayure & 56540.07 & 34914.58 & 247 & 0.77 & 3.08 \\
\hline Escazú & 3455.27 & 1077.39 & 119 & 0.87 & 3.31 \\
\hline Tibás & 833.72 & 56.37 & 29 & 0.84 & 3.61 \\
\hline Desamparados & 11939.62 & 7156.94 & 313 & 0.77 & 4.02 \\
\hline Aguirre & 55673.49 & 33354.81 & 451 & 0.55 & 4.15 \\
\hline Esparza & 21807.08 & 8425.93 & 155 & 1.04 & 4.17 \\
\hline Alajuela & 39143.60 & 19612.93 & 225 & 0.94 & 4.21 \\
\hline Coto Brus & 94267.04 & 70708.76 & 549 & 0.63 & 4.60 \\
\hline $\begin{array}{l}\text { Santo } \\
\text { Domingo }\end{array}$ & 2522.20 & 1067.28 & 203 & 0.97 & 4.65 \\
\hline Curridabat & 1619.50 & 228.35 & 71 & 0.97 & 4.90 \\
\hline Grecia & 39734.22 & 17583.64 & 267 & 0.83 & 5.00 \\
\hline Guácimo & 58031.35 & 32908.99 & 390 & 0.77 & 5.26 \\
\hline $\begin{array}{l}\text { Vázquez de } \\
\text { Coronado }\end{array}$ & 22390.71 & 11134.62 & 296 & 0.93 & 5.51 \\
\hline Corredores & 62467.34 & 24504.54 & 450 & 0.50 & 5.73 \\
\hline Abangares & 64453.77 & 31663.84 & 348 & 0.86 & 6.06 \\
\hline Talamanca & 281639.91 & 97896.67 & 379 & 0.57 & 6.18 \\
\hline San Ramón & 102072.92 & 62517.80 & 475 & 0.80 & 6.20 \\
\hline Alfaro Ruiz & 15772.14 & 5457.04 & 233 & 0.95 & 6.41 \\
\hline Alvarado & 7959.31 & 4176.13 & 405 & 0.86 & 6.61 \\
\hline Limón & 176767.30 & 102407.59 & 802 & 0.52 & 7.13 \\
\hline Cañas & 69082.22 & 19522.29 & 263 & 0.79 & 7.37 \\
\hline Orotina & 14559.65 & 2890.75 & 163 & 0.95 & 7.81 \\
\hline Matina & 77098.21 & 49639.17 & 1052 & 0.50 & 8.15 \\
\hline Puntarenas & 181929.30 & 112860.27 & 645 & 0.79 & 8.22 \\
\hline Liberia & 144306.62 & 46978.46 & 344 & 0.80 & 8.41 \\
\hline Tilarán & 66755.25 & 30086.82 & 403 & 0.97 & 8.70 \\
\hline Paraíso & 47737.64 & 14677.37 & 395 & 0.72 & 9.22 \\
\hline
\end{tabular}


Carlos Morera-Beita - Luis Fernando Sandoval-Murillo

Fragmentación y conectividad de la cobertura natural a nivel cantonal en Costa Rica durante los años 2000 y 2015

\begin{tabular}{|l|r|r|r|r|r|}
\hline Turrialba & 158749.68 & 104552.08 & 1302 & 0.48 & 9.55 \\
\hline Santa Cruz & 132084.12 & 60995.77 & 522 & 0.90 & 10.14 \\
\hline Siquirres & 85481.31 & 46741.57 & 930 & 0.62 & 10.56 \\
\hline La Cruz & 138745.41 & 38867.79 & 378 & 0.85 & 11.43 \\
\hline Oreamuno & 20189.74 & 9657.97 & 630 & 0.88 & 11.60 \\
\hline Cartago & 27765.05 & 12004.52 & 562 & 0.90 & 11.64 \\
\hline Upala & 158328.82 & 66135.24 & 571 & 0.87 & 11.87 \\
\hline Pérez Zeledón & 190091.42 & 131773.75 & 1311 & 0.63 & 11.89 \\
\hline Nicoya & 133925.18 & 63593.76 & 699 & 0.92 & 13.61 \\
\hline Sarapiquí & 214551.94 & 100028.63 & 679 & 0.98 & 14.23 \\
\hline
\end{tabular}

Fuente: Elaboración propia

\section{Anexo 3. Baja fragmentación para los cantones para los años 2000 y 2015.}

\begin{tabular}{|l|c|c|c|c|c|}
\hline \multicolumn{1}{|c|}{ Cantón } & $\begin{array}{c}\text { Área } \\
\text { Cantón }\end{array}$ & $\begin{array}{c}\text { Cobertura } \\
\text { Natural }\end{array}$ & $\begin{array}{c}\text { Numero de } \\
\text { Fragmentos }\end{array}$ & $\begin{array}{c}\text { Vecino más } \\
\text { Cercano }\end{array}$ & $\begin{array}{c}\text { Índice de } \\
\text { Fragmentación }\end{array}$ \\
\hline Acosta & 34166.59 & 23190.17 & 180 & 0.66 & 1.76 \\
\hline Alajuelita & 2148.24 & 1012.37 & 25 & 0.93 & 0.49 \\
\hline Aserrí & 16689.52 & 10299.31 & 155 & 0.87 & 2.18 \\
\hline Barva & 5599.31 & 3065.08 & 101 & 1.04 & 1.93 \\
\hline Belén & 1245.76 & 82.62 & 8 & 0.38 & 0.45 \\
\hline Curridabat & 1619.50 & 312.78 & 14 & 0.96 & 0.69 \\
\hline Desamparados & 11939.62 & 6344.69 & 178 & 0.87 & 2.91 \\
\hline Escazú & 3455.27 & 1084.11 & 57 & 0.90 & 1.63 \\
\hline Flores & 674.22 & 100.94 & 7 & 0.84 & 0.39 \\
\hline Goicoechea & 3164.96 & 1319.84 & 104 & 0.80 & 2.00 \\
\hline Hojancha & 26255.28 & 16014.06 & 235 & 0.77 & 2.98 \\
\hline La Unión & 4443.88 & 2554.86 & 63 & 1.16 & 1.27 \\
\hline León Cortés & 12246.18 & 6740.97 & 159 & 0.98 & 2.83 \\
\hline Montes de Oca & 1555.47 & 427.64 & 19 & 1.04 & 0.72 \\
\hline Moravia & 2911.56 & 954.80 & 63 & 1.04 & 2.00 \\
\hline Naranjo & 12687.08 & 6796.32 & 172 & 0.80 & 2.56 \\
\hline Palmares & 3883.52 & 1649.48 & 80 & 1.07 & 2.01 \\
\hline & & & & & \\
\hline
\end{tabular}


Carlos Morera-Beita - Luis Fernando Sandoval-Murillo Fragmentation and connectivity of the natural cover at county level in Costa Rica, during 2000 and 2015 years

\begin{tabular}{|l|c|c|c|c|c|}
\hline San Isidro & 2646.70 & 1028.69 & 90 & 1.05 & 2.43 \\
\hline San José & 4474.38 & 295.17 & 17 & 0.24 & 0.62 \\
\hline San Pablo & 833.17 & 172.86 & 13 & 1.11 & 0.69 \\
\hline San Rafael & 4804.91 & 3008.66 & 114 & 0.95 & 1.73 \\
\hline Santa Ana & 6135.24 & 2524.81 & 98 & 0.99 & 2.35 \\
\hline Santa Bárbara & 5201.61 & 3336.03 & 148 & 1.06 & 2.44 \\
\hline $\begin{array}{l}\text { Santo } \\
\text { Domingo }\end{array}$ & 2522.20 & 945.28 & 55 & 0.92 & 1.35 \\
\hline Tibás & 833.72 & 98.60 & 17 & 0.97 & 1.39 \\
\hline
\end{tabular}

Baja fragmentación año 2015

\begin{tabular}{|l|c|c|c|c|c|}
\hline Cantón & Área Cantón & $\begin{array}{c}\text { Cobertura } \\
\text { Natural }\end{array}$ & $\begin{array}{c}\text { Numero de } \\
\text { Fragmentos }\end{array}$ & $\begin{array}{c}\text { Vecino más } \\
\text { Cercano }\end{array}$ & $\begin{array}{c}\text { Índice de } \\
\text { Fragmentación }\end{array}$ \\
\hline Carrillo & 59940.75 & 20341.18 & 120 & 0.71 & 2.50 \\
\hline Acosta & 34166.59 & 28372.69 & 56 & 0.61 & 0.41 \\
\hline Alajuelita & 2148.24 & 1009.66 & 90 & 0.92 & 1.77 \\
\hline Aserrí & 16689.52 & 13111.58 & 164 & 0.62 & 1.29 \\
\hline Barva & 5599.31 & 3995.12 & 31 & 0.88 & 0.38 \\
\hline Belén & 1245.76 & 93.43 & 17 & 0.68 & 1.55 \\
\hline Flores & 674.22 & 42.89 & 14 & 0.69 & 1.53 \\
\hline Goicoechea & 3164.96 & 1349.81 & 98 & 1.03 & 2.37 \\
\hline Hojancha & 26255.28 & 18028.32 & 151 & 0.71 & 1.57 \\
\hline La Unión & 4443.88 & 2232.48 & 135 & 0.84 & 2.26 \\
\hline León Cortés & 12246.18 & 10582.27 & 104 & 0.57 & 0.68 \\
\hline Montes de Oca & 1555.47 & 532.27 & 79 & 1.12 & 2.59 \\
\hline Moravia & 2911.56 & 1250.62 & 107 & 0.89 & 2.22 \\
\hline Naranjo & 12687.08 & 9795.40 & 39 & 0.57 & 0.29 \\
\hline Palmares & 3883.52 & 2573.56 & 20 & 0.71 & 0.21 \\
\hline San Isidro & 2646.70 & 1280.60 & 114 & 0.85 & 2.01 \\
\hline San Pablo & 833.17 & 268.02 & 49 & 1.02 & 1.55 \\
\hline San Rafael & 4804.91 & 3334.26 & 97 & 0.73 & 1.02 \\
\hline Santa Ana & 6135.24 & 2770.61 & 45 & 1.10 & 1.10 \\
\hline Santa Bárbara & 5201.61 & 4090.54 & 68 & 1.01 & 0.88 \\
\hline Atenas & 12646.65 & 6149.83 & 52 & 1.00 & 1.07 \\
\hline Dota & 40395.32 & 34358.84 & 94 & 0.76 & 0.84 \\
\hline Garabito & 31331.12 & 16206.95 & 149 & 0.88 & 2.53 \\
\hline & & & & & \\
\hline
\end{tabular}


Carlos Morera-Beita - Luis Fernando Sandoval-Murillo

Fragmentación y conectividad de la cobertura natural a nivel cantonal en Costa Rica durante los años 2000 y 2015

\begin{tabular}{|l|c|c|c|c|c|}
\hline Heredia & 28291.82 & 10257.76 & 134 & 0.80 & 2.94 \\
\hline Jiménez & 25068.48 & 16702.86 & 237 & 0.60 & 2.14 \\
\hline Montes de Oro & 24806.23 & 14646.60 & 143 & 0.76 & 1.85 \\
\hline Mora & 16364.88 & 13401.53 & 27 & 0.98 & 0.32 \\
\hline Parrita & 47737.24 & 24397.97 & 205 & 0.72 & 2.88 \\
\hline Poás & 7441.07 & 4837.84 & 47 & 0.71 & 0.51 \\
\hline Puriscal & 55607.57 & 40181.57 & 178 & 0.42 & 1.04 \\
\hline San Mateo & 12405.39 & 5706.08 & 71 & 1.02 & 1.58 \\
\hline Tarrazú & 29272.64 & 26785.17 & 82 & 0.71 & 0.63 \\
\hline Turrubares & 41582.03 & 27709.84 & 154 & 0.62 & 1.43 \\
\hline Valverde Vega & 13685.42 & 6445.50 & 103 & 0.88 & 1.93 \\
\hline
\end{tabular}

Fuente: Elaboración propia 